\title{
Is Online Transgender Healthcare the Future? An Opinion
}

\author{
Michael AB Naafs* \\ Department of Endocrinology,Health Consultant at Naafs, Netherlands
}

Received: 海 August 17, 2018; Published: 眥 August 24, 2018

*Corresponding author: Michael AB Naafs, Department of Endocrinology, Health Consultant at Naafs Health Consultancy, International Health Consultancy, Rhodoslaan 20,7577 KN, Oldenzaal, Netherlands

\begin{abstract}
Do It-Yourself (DIY) use of hormones in the transgender population is increasing due to waiting lists of 2-3 years to the first appointment in a transgender healthcare center (THC). A "gate keeping" model, psychological assessment procedures and supposed highly specialized endocrinological treatments all contribute to these long waiting lists However, there is no reason why trained competent primary care physicians would not be able to support and accompany transgender people in hormonal replacement therapy. Online treatment by trained primary care physicians offers a solution for the growing waiting lists. In addition THCs should leave their personal kingdoms and go the same way in favor of the safety of transgender people.
\end{abstract}

\section{Introduction}

The access to gender affirmation services is becoming more difficult in most Western countries. Transgender people are waiting up to two and 2,5 years in the U.K. from receiving a GP referral to getting a first appointment [1]. In the Netherlands, the situation is not much better [2]. In the U.S the situation is complicated by unassurance and discrimination [3]. Transgender healthcare centers (THCs) are interdisciplinary centers as trans identities have been considered historically from a psycho- medical rather than a social perspective on sex and gender identity [4,5]. Consequently, both research and practice in the fields of medicine and psychology have sought to distinguish between "real" and "unreal" transsexual people obliging trans individuals to convince health professionals of their trans identity to gain access to transition related healthcare [5]. This "gate keeper" system leaves little room for trust and individuality. THCs might include for instance, cross-sex hormone treatment, gender affirming surgeries, hair removal and voice surgery. Generally, THC professionals are rare and mostly located in urban areas, making access to THCs a practical and financial issue for many individuals.

Prevalence figures vary greatly, due to a highly diverse methodology depending on criteria used of gender dysphoria, transsexualism, gender identity disorder diagnosis, or gender ambivalence or incongruence as the widest diagnosis. Therefore, prevalence figures range from $0,0043 \%$ to $3,9 \%$. Studies have based these analyses on different samples such as clinical and population samples the studies using clinical samples, should be seen as a minimum estimate, as not all trans individuals seek medical treatment [6]. Increasing amount of information leads to more awareness, especially in parents of prepubertal trans children [7]. Bottleneck number one in the long waiting lists is worldwide the psychological assessment procedure and or psychiatrist consultations. A shortage of these "highly trained" health professionals is uniformly present. The policy to make one or two centers gatekeepers for these procedures is not really working. Questions raise if this traject can't be followed in peripheral nonacademic centers [8]. Competent, culturally appropriate clinical services and research depend upon methodologically sound assessment, but it is unclear whether appropriate self-report or clinician-rated assessment tools for adults exist [9]. The next bottleneck is cross-hormonal treatment by "highly specialized endocrinologists". However, hormone regimen for transsexual persons are not so complex or sophisticated that not every endocrinologist could handle these regimens. For pediatric trans patients with upcoming puberty and growth, treatment by pediatric endocrinologists can be defended [10].

Cross hormone self-treatment by transgenders is increasingly used by those who can't stand the waiting list and psychological assessment anymore, totally 3 years, before initiating hormonal treatment. Rotondi et al. examined the extent of nonprescribed hormone use bought by the internet and self-performed surgeries 
among transgender or transsexuals (trans) in Ontario, Canada. They performed a survey research from the Transe Pulse Project. A total of 433 participants were recruited from 2009 to 2010 through respondent -driven sampling. An estimated 43\% (95\% CI;34,9-51,5) of Ontarians were using hormones. Of these a quarter had ever obtained hormones from nonmedical sources (e.g. friend or relative, street or strangers, internet pharmacy, herbals or supplements). Fourteen participants (6,4\%;95\% CI:0,89,0 ) reported at that time taking nonprescribed hormones. Five indicated having performed attempted surgical procedures on themselves (orchiectomy or mastectomy). The authors concluded that past negative experiences with health care providers, along with limited financial resources and a lack to access to THCs may contribute nonprescribed hormone use and self-performed surgeries. [11]

The prevalence of DIY (Do-It Yourself) hormone use in this study [11] is relatively low compared with other studies [12-15]. This may have been due to low reporting of DIY hormone use. It is obvious that DIY use of hormones carries increased risks on acute and longterm effects of hormone therapy, as the latter are largely unknown $[16,17]$. Extensive personal experience in transgender treatment in THCs has also created personal kingdoms limiting access further [17]. How about when this patient group will be embraced by online treatment? The American Academy of Family Physicians and other associations of primary care physicians are increasingly encouraging their members to provide transition -related care to patients with gender dysphoria. But many unspecialized physicians hesitate, citing fear of making mistakes and lack of knowledge and in some cases acknowledging bias. As a result of all these factors, transgender people living in rural and exurban areas are often faced with a vacuum of doctors who want to do the" bread and butter" work, as it is called by Keren Landman MD [18].This includes prescribing and adjusting hormone replacement therapy, and related medication, ordering and reviewing lab results, responding to concerns about medication side effects and monitoring patient's overall health during hormone replacement therapy. While medical educators are beginning to catch up with the demand for transcompetent doctors there is still a long way to go.

Queer Med started mid-2017. Before opening Dr Izzy, Lowell ran a brick and mortar clinic specializing in transgender medicine for two years. She made the change to telehealth and reaching rural patients became her main goal [18]. Dr Katie Bast provides gender affirming primary care as one of several physicians contracted with telehealth practice Steady MD. Bast opened Mosaic, an LGBTQinclusive clinic in Indiana, at mid-2016, before transferring to Steady MD in 2017.Demand is high from all regions of the U.S. and several other countries but Bast and Lowell can only deliver care in states where they are licensed [18]. Anyway, when doctors and THCs embrace virtual treatment models waiting lists and limited access to THCs will be obsolete in the future. Safety of transgenders and DIY hormone users is served by these initiatives.

\section{Conclusion}

Access to transgender health care centers (THCs) is hampered at present by the "gate keeping" model which is not really working, this results in waiting lists of 2-3 years after referral by a GP to the first appointment in a THC. Psychological assessment procedures and hormonal treatment by "highly specialized" endocrinologists are the main obstacles. However, there is no reason why competent trained primary care physicians would not be able to support and accompany transgender persons in hormone replacement therapy. This will prevent the increasing DIY (Do-It Yourself) use of hormones and will serve the safety of transgender people. As the need is high and distances are great this should be performed preferably by online virtual treatments. In addition, THCs should leave their personal kingdoms in the same way. Only then, long waiting lists will be obsolete in the future

\section{References}

1. Westcott H (2018) Transgender people face two-year wait for NHS appointment. BBC News Online; Jan.30.

2. Sharp N (2017) Being Transgender and Seeking Health Care in the World's Most Liberal City. Independent Study Project (ISP) Collection 2649.

3. Grant JM, Mottet LA, Tanis J (2011) A Report of the National Transgender Discrimination Survey; Washington National Center for Transgender Equality and National Gay and Lesbian Taskforce.

4. Meyerowitz J (2002) How Sex Changed-A History of Transsexuallity in the United States. Harvard University Press.

5. Nieder TO, Richter-Appolt H (2011) Tertium non datur-either or reactions to transsexualism amongst health care professionals: the situation past and present, and its relevance to the future. Psychology \& Sexuality 2(3): 224-243.

6. (2013) The European Union Agency for Fundamental Rights publishes the European Union lesbian, gay bisexual and transgender survey. Eurosurveillance editorial team. Euro Surveill 30: 18(22).

7. Ehrensaft D, Grammattei S, Storck K (2018) Prepubertal social gender transitions: What we know; what we can learn-A view from a gender affirmative lens. Int J.Transgenderism 45(2): 251-268.

8. Grant K (2018) Canada's trans people face lengthy wait times for medical care. The Globe and Mail; May 13.

9. Shulman GP, Holt NR, Hope DA, et al. (2017) A review of TGNC-Related Matters. American Psychylogical Associaton.

10. Hembree WC, Cohen-Kettenis P, Delammare-van de Waal HA (2009) Endocrine Treatment of Transsexual Persons: An Endocrine Society Practice Guideline. J Clin Endocrinol Metab 94(9): 3132-3154.

11. Rotondi NK, Bauer GR, Scanlon K, Kaay M, Traavers R, et al. (2013) Nonprescribed Hormone Use and Self-Performed Surgeries: "Do-ItYourself "Transitions in Transgender Communities in Ontario, Canada. Am J Public Health 103(10): 1830-1836.

12. Xavier J (2000) Final Report of the Washington Transgender Needs Assessment Survey, Washington D.C. Administration for HIV and Aids. Government of the District of Colombia.

13. Garofolo R, Deleon J, Osmer E (2006) Overlooked, misunderstood and at-risk: exploring the lives and HIV risk of ethnic minority male-to female transgender youth. J Adolesc Health 38(3): 230-236.

14. Clements-Nolle K, Marx R, Guzman R (2001) HIV prevalence, risk behaviors, health care use, and mental health status of transgender 
persons: :implications for public health intervention. Am J Public Health 91(6): 915-921.

15. Sanchez NF, Sanchez JP, Danoff A (2009) Health care utilization, barriers to care, and hormone usage among male-to female transgender persons in New York City. Am.J. Public Health 99(4): 713-719.

16. Melton CL (2017) Cross-Sex Hormone Therapy: What Are the Long-Term Risk Factors. Endocrinology Advisor; Sept.1.

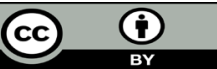
Commons Attribution 4.0 License

Submission Link:

Submit Article

DOI: $10.32474 /$ OAJRSD.2018.01.000116

17. Gooren L, Giltay EJ, Bunck MC (2008) Long-Term Treatment of Transsexuals with Cross-Sex Hormones: Extensive Personal Experience. J Clin Endocrinol Metab 93(1): 19-25.

18. Landman K (2018) The Future of Transgender Healthcare is Online. Vice LQBTQ; Jan 11.
Open Access Journal of Reproductive System and

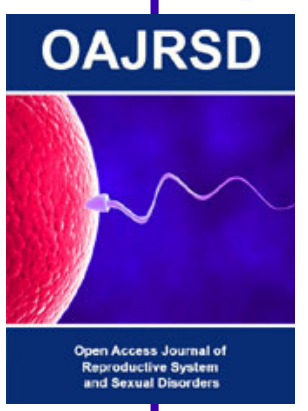
Sexual Disorders

\section{Assets of Publishing with us}

- Global archiving of articles

- Immediate, unrestricted online access

- Rigorous Peer Review Process

- Authors Retain Copyrights

- Unique DOI for all articles 